\title{
Sensory Nerve Conduction Velocity in Normal Children Below Five Years of Age
}

\author{
Md. Zabihullah' ${ }^{1}$ Dhirendra Kumar Agrawal' ${ }^{2}$ Tabassum Shahab ${ }^{3}$ \\ ${ }^{1}$ Assistant Professor, Department of Physiology, GS Medical College and Hospital, Pilkhuwa, Hapur, Uttar \\ Pradesh, India, ${ }^{2}$ Ex. Professor and Chairman, Department of Physiology, ${ }^{3}$ Ex. Professor, Department of \\ Paediatrics, Jawaharlal Nehru Medial College and Hospital, Aligarh, Uttar Pradesh, India
}

\begin{abstract}
Background: Peripheral nervous system development begins in prenatal period and continues after birth up to 5 years of age. As a result, Sensory nerve conduction velocity (SNCV) varies during first five years of life of children.

Aims and Objectives: The purpose of this study is evaluation of the SNCV of median, ulnar and sural nerve during the first five years of life.

Material and Method: SNCV of median, ulnar and sural nerves was measured antidromically in 104 normal under-five children. Statistical analysis of the results was done using SPSS 17.0 software.

Results: There was a progressive increase in SNCV of median, ulnar and sural nerves with age. SNCV of all three nerves showed significant positive correlation with age factor.

Conclusion: There is significant increase in SNCV of median, ulnar, and sural nerves with age in under-five children. Therefore, age-specific reference values of SNCV for the different nerves in children below 5 years of age are important to evaluate nerve injury or maturational deficit.
\end{abstract}

Key Words: Sensory Nerve Conduction Velocity (SNCV), Children, Peripheral nervous system

\section{Introduction}

Infancy and early childhood are crucial periods in the development of the central nervous system and this critical period in humans extends from the third month of pregnancy to 2 years of age. ${ }^{1}$ Myelination of Peripheral nerve also occurs around this critical period, beginning at 15 th week of gestation ${ }^{2}$ and continuing throughout the first 2 to 5 years of life ${ }^{3-4}$. Axons also undergo progressive maturation during this period, reaching a maximum between ages two and five years. ${ }^{5}$

\footnotetext{
Corresponding Author:

Dr. Md. Zabihullah,

Flat No. 404, Teaching Staff Quarters,

GS Medical College, Pilkhuwa, Hapur-245304,

Uttar Pradesh, India.

E-mail: drzabihullah81@gmail.com
}

The ongoing maturation of peripheral nerves in children can be evaluated by measuring conduction velocity as it depends on degree of myelination, diameter of the nerve fibres and internodal distances. The relationship between motor nerve conduction velocity and age has been studied by many authors. ${ }^{6-7}$ However, very few studies have been reported on normal sensory nerve conduction velocity (SNCV) during first years of life when nerves undergo maturation. Hence, we planned this study to evaluate the SNCV in normal infants and children below the age of 5 years.

\section{Materials and Method}

The present prospective cross sectional study was conducted in Neurophysiology Laboratory, Department of Physiology, Jawaharlal Nehru Medical College, Aligarh Muslim University, Aligarh. The approval of Institutional Ethical Committee was obtained prior to the commencement of study. An informed consent was 
taken from parents/ guardians of all children before conducting the test. Study sample consisted of 104 healthy children below the age of 5 years born at term, attending the Paediatrics outpatient department for regular check-ups. Subjects having any neuromuscular disorder were excluded from the study.

Sensory nerve conduction velocity test was performed on median, ulnar and sural nerves with Neuroperfect EMG/NCV/EP System. SNCV was measured antidromically by stimulating at a single stimulation site. The distance between the recording electrode and the stimulation site was measured. SNCV was calculated by dividing the distance between the stimulating and recording sites by the latency. ${ }^{8}$

\section{Statistical Analysis}

Statistical analysis of the results was done using SPSS 17.0 software. One-way ANOVA tests and Pearson's correlation were used to analyse the results. A value of $p$ less than 0.05 was considered statistically significant.

\section{Results}

Sensory nerve conduction velocity (SNCV) of median, ulnar, and sural nerve was evaluated in 104 healthy children below 5 years of age. Statistical analysis was done by dividing the children in six age groups.

Table 1: Age and sex distribution of study subjects

\begin{tabular}{|l|l|l|l|}
\hline \multirow{2}{*}{ Groups } & \multirow{2}{*}{$\begin{array}{l}\text { Age } \\
\text { (Months) }\end{array}$} & Sex & Female \\
\cline { 3 - 4 } & $0-6$ & 8 & 5 \\
\hline Group 1 & $>6-12$ & 9 & 7 \\
\hline Group 2 & $>12-24$ & 9 & 10 \\
\hline Group 3 & $>24-36$ & 10 & 9 \\
\hline Group 4 & $>36-48$ & 11 & 8 \\
\hline Group 5 & $>48-59$ & 10 & 8 \\
\hline Group 6 & & & \\
\hline
\end{tabular}

Table 2: Comparison of mean sensory nerve conduction velocity (SNCV) of median nerve, ulnar nerve and sural nerve between the six age groups using one-way ANOVA

\begin{tabular}{|c|c|c|c|c|c|c|c|}
\hline \multirow{2}{*}{ Parameters } & \multicolumn{6}{|l|}{ Mean \pm SD } & \multirow{2}{*}{ p-Value } \\
\hline & Group 1 & Group 2 & Group 3 & Group 4 & Group 5 & Group 6 & \\
\hline $\begin{array}{l}\operatorname{SNCV}(\mathrm{m} / \mathrm{s}) \\
\text { (Median } \\
\text { Nerve) }\end{array}$ & $29.33 \pm 2.45$ & $37.73 \pm 3.16$ & $43.52 \pm 2.60$ & $46.57 \pm 2.71$ & $48.73 \pm 3.15$ & $50.95 \pm 1.77$ & $<0.001^{*}$ \\
\hline $\begin{array}{l}\mathrm{SNCV}(\mathrm{m} / \mathrm{s}) \\
\text { (Ulnar Nerve) }\end{array}$ & $29.90 \pm 2.29$ & $38.54 \pm 3.08$ & $43.74 \pm 2.01$ & $47.54 \pm 1.91$ & $49.03 \pm 2.12$ & $51.28 \pm 2.21$ & $<0.001^{*}$ \\
\hline $\begin{array}{l}\mathrm{SNCV}(\mathrm{m} / \mathrm{s}) \\
\text { (Sural Nerve) }\end{array}$ & $29.45 \pm 2.97$ & $34.92 \pm 2.40$ & $39.54 \pm 2.05$ & $45.14 \pm 2.43$ & $48.59 \pm 3.03$ & $50.78 \pm 1.85$ & $<0.001^{*}$ \\
\hline
\end{tabular}

$* \mathrm{p}<0.05$ significance. $\mathrm{SD}=$ Standard deviation 
Table 3: Pearson's correlation analysis of effects of age on sensory nerve conduction velocity (SNCV) in the study subjects

\begin{tabular}{|l|l|l|l|}
\hline Nerve & Parameters & r-Value & p-Value \\
\hline Median nerve & Sensory nerve conduction velocity & 0.863 & $<0.001$ \\
\hline Ulnar nerve & Sensory nerve conduction velocity & 0.874 & $<0.001$ \\
\hline Sural nerve & Sensory nerve conduction velocity & 0.927 & $<0.001$ \\
\hline
\end{tabular}

Correlation is significant at the 0.05 level

SNCV for median, ulnar and sural nerve for the six age groups are shown in table 2. SNCV was found to increase progressively from Group1 to Group6 for all the three nerves. One-Way ANOVA test was used for comparing the mean SNCV of median nerve, ulnar nerve and sural nerve between different age groups and was found statistically significant $(\mathrm{p}<0.05)$.

Correlation between age and SNCV of median, ulnar, and sural nerve is shown in table 3. Analysis of correlation between age and SNCV was done using Pearson's correlation. A significant positive correlation was found between age and SNCV of median nerve ( $\mathrm{r}-$ value $=0.863)$, ulnar nerve $(\mathrm{r}-$ value $=0.874)$, and sural nerve $(r-$ value $=0.927)$.

\section{Discussion}

Our study assessed the SNCV of median, ulnar, and sural nerve in normal children below the age of five years. The study subjects were divided into 6 age groups. The mean SNCV of all three nerves were found to increase progressively with age, highest being in group 6 comprising children of age group $>48-59$ months. Significant positive correlation was found between age and the SNCV for all the three nerves. Similar results have been reported by earlier investigators. ${ }^{9-11}$

SNCV depends on degree of myelination, distances between nodes of Ranvier, and diameter of the fibres. ${ }^{12}$ Majority of myelin is assembled during the first few years of life. Very rapid myelin synthesis early in development has been demonstrated biochemically by earlier investigaors. ${ }^{13}$ Actually Schwann cells begins myelination of nerves in fetal life and it is completed by 5 years of age. ${ }^{14}$ Axons also mature simultaneously and reach a peak between 2 to 5 years of age. ${ }^{5}$ There exists a direct relationship between the diameter of the nerve fibre and the thickness of the myelin sheath. Remodelling of the nodes of Ranvier also occurs in the first few years of children's life with internodal distances varying linearly with fibre diameter. ${ }^{15}$ The significant increase in SNCV of median, ulnar, and sural nerves with age may be explained by varying maturational stages of these nerves. Therefore, age-specific reference values of SNCV for the different nerves in children below 5 years of age are important to evaluate nerve injury or maturational deficit.

\section{Conclusion}

To conclude, SNCV of median, ulnar, and sural nerve increase progressively with age in children below five years of age. It may be due to the ongoing maturation of determinants of conduction velocity of peripheral nerves but future studies should also evaluate the SNCV in children above five years of age.

\section{Source of Support: Nil}

\section{Conflict of Interest: None}

\section{References}

[1] Morgane PJ, Austin-LaFrance R, Bronzino J, et al. Prenatal malnutrition and development of the brain. Neurosci Biobehav Rev 1993;17(1):91-128.

[2] Gamble HJ, Breathnach AS. An electronmicroscope study of human foetal peripheral nerves. J Anat 1965;99(Pt 3):573-84.

[3] Cottrell L. Histologic variations with age in apparently normal peripheral nerve trunks. Arch Neurol 1940;43(6):1138-50.

[4] Rexed B. Contribution to knowledge of postnatal development of peripheral nervous system in 
man: study of bases and scope of systematic investigations into fibre size in peripheral nerves. Acta Psychiatry Neurol Scand Suppl 1944;33:1206

[5] Thomas JE, Lambert EH. Ulnar nerve conduction velocity and H-reflex in infants and children. J Appl Physiol 1960;15:1-9.

[6] Ja Cho, Kyoung. (1987). Motor Nerve Conduction Velocity in Newborn Infants and Children. Yonsei medical journal. 28. 172-5. 10.3349/ ymj.1987.28.3.172

[7] Guchhait B, GuptaS, Sau AK, Sen S. "Evaluation of Motor NCS Parameters between Upper and Lower Limbs and Their Pattern of Maturation in Infants and Children." IOSR Journal of Dental and Medical Sciences (IOSR-JDMS), vol. 18, no. 1, 2019, pp 52-57

[8] Misra UK, Kalita J. Principles of nerve conduction velocity. In: Clinical neurophysiology. 3rd edn. New Delhi: Elsevier India 2014:21-9.

[9] Gamstorp I, Shelburne SA : Peripheral sensory conduction in ulnar and median nerves of normal infants, children and adolescents, Acta Pediat Scand 1965; $54: 309-313$.

[10] García, A \& Calleja, Jesús \& M Antolín, F \& Berciano, José. (2000). Peripheral motor and sensory nerve conduction studies in normal infants and children. Clinical neurophysiology: official journal of the International Federation of Clinical Neurophysiology. 111. 513-20. 10.1016/S13882457(99)00279-5.

[11] Guchhait B, Sen S, Ganguly G, Sinha M: Peripheral Motor and Sensory nerve conduction studies in normal infants and children in Eastern India, Journal of Dental and Medical sciences,2014(Aug);13(8):26-32

[12] Barrett KE, Barman SM, Boitano S, et al. Excitable tissue: nerve. In: Ganong's review of medical physiology. 25th edn. New Delhi: McGraw-Hill 2016:85-98.

[13] Quarles RH, Macklin WB, Morell P. Myelin formation, structure and biochemistry. Elsevier Publishing 1999: P. 67-8.

[14] Webster HF, Favilla JT. Development of peripheral nerve fibers. In: Dyck PJ, Thomas PK, Lambert EH, Bunge R, editors. Peripheral neuropathy, vol. 1, 2nd ed. Philadephia: WB Saunders 1984; 329359.

[15] Vizoso, A.D. \& Z YOUNG, J. (1948). Internode length and fibre diameter in developing and regenerating nerves. Journal of anatomy 1948; 82: 110-34. 